of sectarian groups on risks reflect their rebellion against the centre and their own needs to maintain group allegiance. Their views are marked by "disdain of the world, fear of pollution, of cancerous contamination" and are propelled by "moral fervor". The sectarian "wins adherence if he can threaten bigger dangers and associate them with the corruption of the system",

The authors develop their model of the sectarian society less from evidence than from their own opinion of the radical wing of the environmental movement. They quickly lapse into pejorative language that hardly masks their disdain. They portray such groups as self-indulgent and living in permanent and nagging opposition to the centre with no intention of assuming responsibility or power. And they denigrate the strengths of sectarian ideals suggesting that, when not allowed to enjoy government subsidy, such groups simply become part of the very system they reject.

The authors feel that such sectarian values are increasingly important in American society and have won "extraordinary success". They do, indeed, account for our preoccupation with risk. There are, however, many problems with their argument. After all, the "sustained assault" by public interest and environmental groups lasted but a decade. In the context of today's politics the "extraordinary success" of environmental groups as compared to business interests is hardly convincing. Moral fervour in the United States today comes from other directions, indeed from the centre itself. Concerned about challenges to the hierarchical and market values that constitute the centre, the authors ignore the usefulness of sectarian groups as a source of constructive criticism and countervailing power. They neglect, for example, the positive contributions of "border groups"' such as the alternative technology movement who have put forward specific proposals for minimizing risk. And to suggest that such sectarian - i.e. powerless groups could gain power if they really wanted it, is to totally ignore political and economic constraints. In their criticism of such groups, the authors describe "lobbying, litigation and non-violent obstruction" as "border strategies", forgetting that these are also conventional political actions exploited by bureaucracies and businesses.

The authors also dismiss the possibility that the reality of risk has changed in any significant way, essentially ignoring the increased scale and changing character of technology-induced risk. Associating the fear of risk with radical groups, their theory has no place for those who work in genuinely dangerous jobs, or the residents of Love Canal, or the 700,000 middle-class people who converged in New York City to protest against the risk of nuclear war.

A cultural theory of risk could be developed in a different direction with greater emphasis on the social position and the special vulnerability of certain groups with limited economic or political choice. It could call attention to the experience and perspectives of people who deal with risks as a fact of everyday life. Clearly judgements of risk reflect cultural values. But after all there is a social reality. If indeed the issue of risk has become an arena for disputes over power, why not take off from this approach to examine critically corporate perceptions and behaviour with respect to risk? Why not ask how factors at work and in daily life influence people's risk perceptions?

Douglas and Wildavsky end their book by frankly stating their own bias towards the centre. Basing their analysis on the acceptance of given institutional arrangements, they, along with other risk analysts, have masked many problems by avoiding critical questions about the very political and social relationships that they themselves admit are fundamental to the selection and perception of risks.

Dorothy Nelkin is a Professor in the Cornell University Program on Science, Technology and Society and the Department of Sociology.

\section{An enlarged Universe}

\section{Owen Gingerich}

The Expanding Universe: Astronomy's 'Great Debate' 1900-1931. By Robert W. Smith. Pp.220. ISBN 0-521-23212-0. (Cambridge University Press: 1982.) $£ 19$, $\$ 29.50$.

ONE of the extraordinary developments of twentieth-century science has been the recognition and measurement of the great size of the Universe. The most dramatic moments in this revolutionary understanding took place from 1918 to 1924 , primarily at the great mountain observatories in the American West, and a focal event was the debate on the scale of the Universe between Harlow Shapley and H.D. Curtis in Washington, in June 1920.

The Shapley-Curtis debate has achieved something of near mythological status among astronomers. Robert Smith capitalizes on the mystique of the specific debate in his subtitle to extend the argumentation over a broader time span; and well he might, for, as he informs us, the actual encounter before the National Academy of Sciences left a great deal to be desired as far as scientific depth was concerned. The main title is likewise stretched beyond its specific technical connotation, and in an almost punning fashion refers more to a Universe ever larger in man's conception than in physical expansion.

The Shapley-Curtis-Hubble era has attracted a variety of historical treatments in the past decade. Smith's in-depth research fills in the contemporary details too often blurred by our 20-20 hindsight. For example, the status of the globular clusters as possible external galaxies has been almost entirely neglected in modern historical accounts of the 1915-1925 period. Similarly, he fills in the story of the first faltering attempts in the 1920 s to derive a relation between the velocities and distances of the spirals, without which certain aspects of Edwin Hubble's approach to the problem can scarcely be comprehended.

In giving us a near-definitive account of the fascinating and turbulent growth in astronomical knowledge, Smith has assiduously avoided the historian's sin of evaluating the past with today's standards. Yet it would have been illuminating, I think, for him to have allowed that Shapley's joining of the period-luminosity relations for cluster-type variables and the Cepheids, for which he was criticized at the time, was in fact incorrect. Equally, Shapley's own criticism of Hubble's assumptions about the similarity of certain galaxies and their components has today proved valid. In the event both Shapley and Hubble pushed on with their faulty programmes, to the considerable advance of science in their day. This may well be telling us something interesting about the nature of scientific progress, but Smith's strictly historical approach prevents any such speculation.

Owen Gingerich is a Professor of Astronomy and History of Science at the HarvardSmithsonian Center for Astrophysics, Cambridge, Massachusetts.

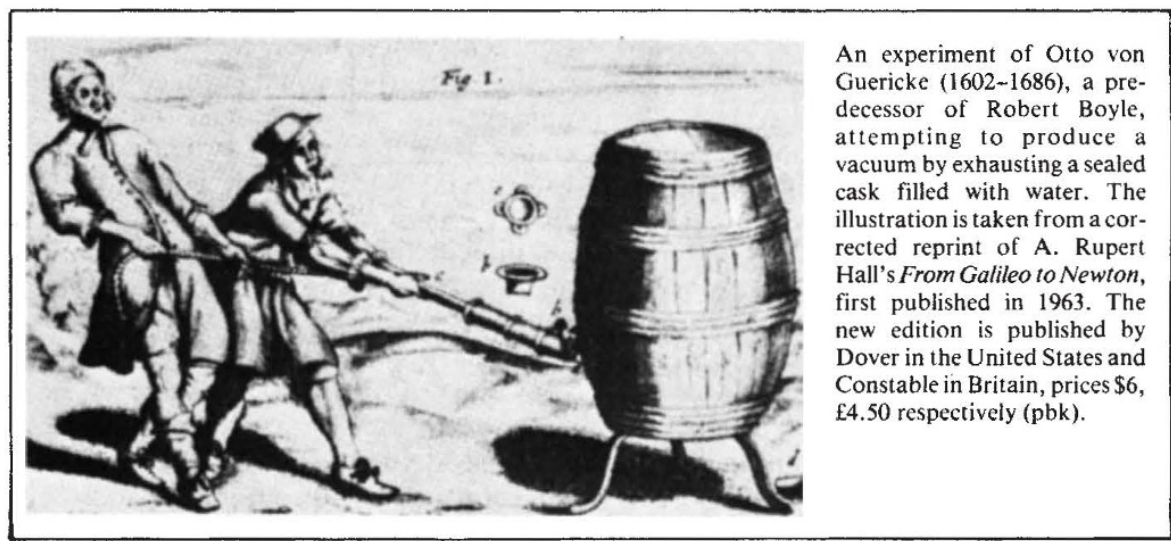

